\title{
Lipid profile in renal transplant recipients receiving immunosuppressive therapy
}

\author{
Samir Lamichhane ${ }^{1 *}$, Sangha Ratna Bajracharya ${ }^{1}$, Dibya Singh Shah ${ }^{2}$
}

\begin{abstract}
${ }^{1}$ Department of Clinical Pharmacology, ${ }^{2}$ Department of Nephrology, Maharajgunj Medical Campus, Institute Of Medicine, Tribhuvan University, Nepal
\end{abstract}

Received: 13 December 2016 Accepted: 03 January 2017

\author{
*Correspondence to: \\ Dr. Samir Lamichhane, \\ Email: \\ dr.samirlamichhane@iom.edu. \\ np
}

Copyright: (c) the author(s), publisher and licensee Medip Academy. This is an openaccess article distributed under the terms of the Creative Commons Attribution NonCommercial License, which permits unrestricted noncommercial use, distribution, and reproduction in any medium, provided the original work is properly cited.

\begin{abstract}
Background: Immunosuppression has been detrimental for graft survival in renal transplant recipients (RTRs). Now that acute rejection is less of a concern, the main problem with kidney transplantation is the long term adverse effects of immunosuppression; dyslipidemia and subsequent atherosclerosis leading to cardiovascular diseases being one of them. The objective of the study was to determine the association of lipid profile with immunosuppressive therapy in RTRs.

Methods: A descriptive qualitative study was conducted in 120 live RTRs following up at the post-renal transplant clinic in 1 year duration. Means of baseline lipid profiles were compared to those of all follow ups and means of all lipid profiles done at different intervals were compared among different subgroups of patients grouped according to different variables including the individual immunosuppressants and the immunosuppressive therapy.

Results: There was a significant increase in TC levels at 6 and 12 months. HDL-C levels were significantly higher at all follow ups and TG levels done at all follow ups were significantly higher as compared to baseline.

LDL-C(12) was significantly higher in the group with higher tacrolimus dose. LDL-C(6), LDL-C(24), TC(24) were significantly different among different prednisolone groups reflecting a relation of prednisolone with alteration in lipid profiles. None of the two regimens was found to be superior over the other regarding lipid profile.

Conclusions: This study has shown a significant alteration of lipid profile in patients after renal transplantation as compared to pre-transplant status and immunosuppressive therapy seems to be one among the various contributors to it.
\end{abstract}

Keywords: Immunosuppressive therapy, Lipid profile, Renal transplant recipients

\section{INTRODUCTION}

Over few decades, kidney transplantation has become one of the important modalities of treatment of end stage renal disease (ESRD) and immunosuppression has become one of the most important reasons for prolonged graft survival. $^{1,2}$ Now that acute rejection is less of a concern than in early years of transplantation, outcome measures are focusing on long term morbidity and survival. With lifelong immunosuppression being one of the cornerstones for the graft survival after a successful renal transplant, the main problem with kidney transplantation these days is the long term adverse effects of immunosuppression; dyslipidemia, subsequent atherosclerosis leading to cardiovascular diseases being one of them. ${ }^{3-10}$ As evidenced by many studies, many of the current immunosuppressive drugs are found to have an association with dyslipidemia and in turn with the development of atherosclerosis. .,11-13 $^{-13}$

Thus, preventing lipid abnormalities and their complications, detection of lipid abnormalities as early as possible after transplantation, subsequent management and minimizing complications are very important parts of post-transplant care. Hence the present study was aimed to determine the association of lipid profile impairment with immunosuppressive therapy in renal transplant recipients (RTRs). 


\section{METHODS}

A descriptive qualitative study was done on 120 live RTRs following up at the post renal transplant clinic at Manmohan Cardiothoracic Vascular and Transplant Center from $1^{\text {st }}$ November, 2013 to $31^{\text {st }}$ October, 2014. The study was approved by the institutional review board of Institute Of Medicine and a written informed consent was obtained from each patient. All follow up RTRs were included except those whose baseline lipid profile was not available, those who were non-compliant with the immunosuppressive regimen and those who had not completed 2 years after transplantation. A study proforma was used to collect all relevant parameters including baseline blood lipid profiles and follow-up blood lipid profiles (6 months, 12 months and 24 months). Particulars of the patients and relevant history were taken; height and weight were measured. All other relevant information including lipid profile were traced through the medical records of the patients and were entered in the study proforma. These included:

\section{Characteristics of the patient (socio-demographic details) and other relevant history}

- Co-morbidities

- Cause of renal failure requiring transplantation

- Date of transplantation and duration since then

\section{Investigations}

- Baseline blood lipid profile (TC, TG, HDL, LDL).

- Follow-up blood lipid profiles (at 6,12 and 24 months post transplantation).

\section{Record of all the medications with individual dose and duration}

- Body Mass Index (BMI) were calculated by using the formula: $\mathrm{BMI}=$ weight $(\mathrm{kg}) /[\text { height }(\mathrm{m})]^{2}$

- All these relevant parameters were entered into the computer software and statistical analyses were done.

- Patients were categorized (grouped) as per the age, sex, BMI, dose of immunosuppressives, use of lipid lowering agents, other co-morbidities (diabetes, thyroid disorders, hepatic dysfunction), use of other medications (diuretics, beta blockers) and analyses were made accordingly (individual impact on lipid profile impairment). Patients were grouped as follows:

- $\quad$ On the basis of age, patients were kept under 3 groups viz $<35$ years, 35 to 50 years and $>50$ years.

- On the basis of gender, patients were classified as male or female.

- On the basis of BMI, patients were classified into 4 groups (as per the CDC classification) viz. $^{14}$
1. $<18.5$ as 'underweight'

2. 18.5 to 24.9 as 'normal weight'

3. 25 to 29.9 as 'overweight' and

4. 30 and above as 'obese'

- On the basis of presence or absence of comorbidities:

1. With or without diabetes

2. With or without thyroid disorder

3. With or without hepatic dysfunction

- On the basis of concomitant medications:

1. Either taking or not taking an antihyperlipidemic

2. Either taking or not taking a beta blocker

3. Either taking or not taking a diuretic

On the basis of dose and frequency of individual immunosuppressant, patients were categorized under several groups and on the basis of immunosuppressive regimen; patients were categorized under 2 groups (as follows):

1. On the basis of individual immunosuppressant:

- Tacrolimus: grouped on two bases

- Individual dosage

- Daily dose of $\leq 1.5 \mathrm{mg}$ and $>1.5 \mathrm{mg}$

- Mycophenolate mofetil: grouped on two bases

- Individual dosage

- Daily dose of $\leq 1000 \mathrm{mg}$ and $>1000 \mathrm{mg}$

- Azathioprine: grouped on two bases

- Individual dosage

- Daily dose of $50 \mathrm{mg}$ and $75 \mathrm{mg}$

- Prednisolone: grouped on three bases

- Individual dosage

- Daily dose of $\leq 5 \mathrm{mg}$ and $>5 \mathrm{mg}$

- Either taking or not taking prednisolone

2. On the basis of immunosuppressive regimen:

- Tacrolimus + Mycophenolate mofetil + Prednisolone $(\mathrm{T}+\mathrm{M}+\mathrm{P})$

- Tacrolimus + Azathioprine + Prednisolone $(\mathrm{T}+\mathrm{A}+\mathrm{P})$

Means of baseline lipid profiles were compared to all follow ups using ' $t$ ' test and means of all lipid profiles were compared among different sub-groups of patients 
grouped according to various parameters like age, sex, BMI, etc. using ANOVA test. A p-value of $\leq 0.05$ was considered to be statistically significant for all the tests.

\section{RESULTS}

Patients ranged from 22-67 years (mean 40yrs). Out of the 120 patients, $100(83.3 \%)$ were male and $20(16.7 \%)$ were female. Among the various age groups, $45(37.5 \%)$ were below 35 yrs out of which $38(31.7 \%)$ were male and $7(5.8 \%)$ were female, $50(41.7 \%)$ were between 35 and 50 yrs age group out of which $40(33.3 \%)$ were male and $10(8.4 \%)$ were female and rest $25(20.8 \%)$ were above 50 years out of which $22(18.3 \%)$ were male and 3 $(2.5 \%)$ were female. Ninety seven $(80.8 \%)$ had normal BMI, $9(7.5 \%)$ were underweight and remaining 14 (11.7\%) were overweight.

Among the various causes of renal failure in these RTRs, hypertension seems to be the most common cause seen in $44(36.7 \%)$ of patients. Cause was unknown in 26 $(21.7 \%)$ of patients. Other causes included chronic glomerulonephritis which accounted for 14 (11.5\%) cases, followed by 9 (7.5\%) cases each of type II diabetes and $\operatorname{Ig}$ A nephropathy (IgAN). About $4.2 \%$ of the patient had both HTN and type II DM as the cause of renal failure. Other causes included $5(4.2 \%)$ cases of obstructive uropathy, $3(2.5 \%)$ cases of Focal Segmental Glomerulosclerosis (FSGS) and $1(0.8 \%)$ case each of Rapidly Progressive Glomerulonephritis (RPGN), Membranoproliferative Glomerulonephritis (MPGN), Autosomal Dominant Polycystic Kidney Diseases (ADPKD), Systemic Lupus Erythematosus (SLE) and Nephrocalcinosis. Diabetes as a co-morbidity was seen in 47 (39.2\%) patients. Similarly, thyroid disorder was present in $16(13.7 \%)$ and hepatic pathology in $2(1.7 \%)$ patients. Among the medications concomitantly used, antihyperlipidemics were prescribed in 40 (33.3\%) patients, beta blockers in $56(46.7 \%)$ patients and diuretics in $2(1.7 \%)$ patients. Patients were under a prednisolone, tacrolimus and mycophenolate mofetil (MMF) or a prednisolone, tacrolimus and azathioprine based immunosuppressive regimen. All patients were taking tacrolimus; 103 (85.8\%) were taking MMF and rest $17(14.2 \%)$ were taking azathioprine; and 118 $(98.3 \%)$ patients were under prednisolone.

Results of comparison of all f/u lipid levels with respective baseline and comparison of all lipid profiles among various groups of patients grouped as described above are shown in tables below. All results are not included. Only those with statistically significant results (as indicated by *) or those very close to significant levels are included.

Total cholesterol at 6 and 12 months were significantly higher than the baseline cholesterol level (Table 1).
Table 1: Comparison of follow up TC levels with baseline and the level of significance.

\begin{tabular}{|lll|l|}
\hline $\begin{array}{l}\text { Parameter } \\
\text { (month) }\end{array}$ & Mean (mg/dl) & Mean SE & 'p'value \\
\hline TC $(0)$ & 157.93 & 3.901 & \\
\hline TC $(6)$ & 172.95 & 4.091 & $0.000^{*}$ \\
\hline TC $(12)$ & 165.89 & 3.614 & $0.031^{*}$ \\
\hline
\end{tabular}

LDL cholesterol at 24 months was significantly different as compared to baseline level (Table 2).

Table 2: Comparison of follow up LDL-C levels with baseline and the level of significance.

\begin{tabular}{|lll|l|}
\hline $\begin{array}{l}\text { Parameter } \\
\text { (month) }\end{array}$ & Mean (mg/dl) & Mean SE & 'p' value \\
\hline LDL-C (0) & 91.33 & 3.362 & \\
\hline LDL-C (12) & 85.12 & 3.426 & 0.089 \\
\hline LDL-C (24) & 79.37 & 3.135 & $0.000^{*}$ \\
\hline
\end{tabular}

All follow up HDL-C levels were significantly different than the baseline HDL-C level (Table 3).

Table 3: Comparison of follow up HDL-C levels with baseline and the level of significance.

\begin{tabular}{|llll|}
\hline $\begin{array}{l}\text { Parameter } \\
\text { (month) }\end{array}$ & Mean (mg/dl) & Mean SE & 'p' value \\
\hline HDL-C (0) & 40.51 & 1.208 & \\
\hline HDL-C (6) & 49.09 & 1.351 & $0.000^{*}$ \\
\hline HDL-C (12) & 46.65 & 1.091 & $0.000^{*}$ \\
\hline HDL-C (24) & 48.25 & 1.354 & $0.000^{*}$ \\
\hline
\end{tabular}

All follow up TG levels were significantly higher than the baseline TG level (Table 4).

Table 4: Comparison of follow up TG levels with baseline and the level of significance.

\begin{tabular}{|llll|}
\hline $\begin{array}{l}\text { Parameter } \\
\text { (month) }\end{array}$ & Mean (mg/dl) & Mean SE & 'p' value \\
\hline TG $(0)$ & 130.12 & 5.965 & \\
\hline TG $(6)$ & 163.80 & 7.621 & $0.000^{*}$ \\
\hline TG $(12)$ & 171.73 & 7.431 & $0.000^{*}$ \\
\hline TG $(24)$ & 162.53 & 8.185 & $0.000^{*}$ \\
\hline
\end{tabular}

Table 5: Lipid profiles with differences among age groups.

\begin{tabular}{|c|c|c|c|c|}
\hline $\begin{array}{l}\text { Lipid } \\
\text { profile }\end{array}$ & $\begin{array}{l}\text { Mean } \\
\text { (mg/dl) } \\
<35 \text { yrs }\end{array}$ & $\begin{array}{l}\begin{array}{l}\text { Mean } \\
(\mathrm{mg} / \mathrm{dl})\end{array} \\
\mathbf{3 5 - 5 0} \text { yrs }\end{array}$ & $\begin{array}{l}\text { Mean } \\
(\mathrm{mg} / \mathrm{dl}) \\
>50 \mathrm{yrs}\end{array}$ & $\begin{array}{l}\text { 'p' } \\
\text { value }\end{array}$ \\
\hline & 168.56 & 155.62 & 181.64 & $0.022 *$ \\
\hline HDL-C & 45.31 & 45.02 & 52.32 & $0.027 *$ \\
\hline LDL-C (12) & 89.18 & 75.67 & 96.32 & 0.051 \\
\hline
\end{tabular}


TC and HDL-C both at 12 months were significantly different among various age groups, the highest among those $>50$ years of age (Table 5 ).

Both TC and LDL-C at 6 months were higher among those taking concomitant diuretics (Table 6).

Table 6: Lipid profiles with level of significance among patients with or without concomitant diuretic.

\begin{tabular}{|llll|}
\hline $\begin{array}{l}\text { Lipid } \\
\text { profile }\end{array}$ & $\begin{array}{l}\text { Mean }(\mathrm{mg} / \mathrm{dl}) \\
\text { With } \\
\text { diuretics }\end{array}$ & $\begin{array}{l}\text { Mean (mg/dl) } \\
\text { Without } \\
\text { diuretics }\end{array}$ & $\begin{array}{l}\text { 'p' } \\
\text { value }\end{array}$ \\
\hline TC (6) & 243.50 & 171.75 & $0.024^{*}$ \\
\hline LDL-C (6) & 150.00 & 90.57 & $0.031^{*}$ \\
\hline
\end{tabular}

LDL-C at 12 months was significantly higher among those taking a daily tacrolimus dose of $>1.5 \mathrm{mg}$ as compared to those taking <1.5 mg per day (Table 7).

Table 7: Lipid profiles with level of significance among different Tacrolimus groups (daily dose $<1.5$ mg or $>1.5 \mathrm{mg})$.

\begin{tabular}{|llll|}
$\begin{array}{l}\text { Lipid } \\
\text { profile }\end{array}$ & $\begin{array}{l}\text { Mean }(\mathrm{mg} / \mathrm{dl}) \\
<1.5 \mathrm{mg}\end{array}$ & $\begin{array}{l}\text { Mean }(\mathrm{mg} / \mathrm{dl}) \\
>1.5 \mathrm{mg}\end{array}$ & $\begin{array}{l}\text { 'p' } \\
\text { value }\end{array}$ \\
\hline $\begin{array}{l}\text { LDL-C } \\
(12)\end{array}$ & 79.03 & 93.24 & $0.040^{*}$ \\
\hline TC (12) & 160.17 & 173.63 & 0.066 \\
\hline $\begin{array}{l}\text { HDL-C } \\
(12)\end{array}$ & 48.33 & 44.37 & 0.073 \\
\hline
\end{tabular}

TC and LDL-C at 24 months were both significantly different among various MMF groups (Table 8). However, there was no correlation of lipid levels with the dose of MMF. Further comparing among those taking $\leq 1$ g/day and $>1 \mathrm{~g} /$ day also didn't reveal any differences to a significant level. Hence concluding no significant role of MMF in dyslipidemia in RTRs.

Table 8: Lipid profiles with statistically significant differences among different MMF groups (according to doses and frequency).

\begin{tabular}{|ll|}
\hline Lipid profile & 'p’ value \\
\hline TC $(24)$ & $0.007^{*}$ \\
\hline LDL-C (24) & $0.002^{*}$ \\
\hline
\end{tabular}

While comparing lipid profiles among various azathioprine groups, statistically significant difference was not seen in any lipid profile.

Further, comparing those taking $50 \mathrm{mg} /$ day with those taking $75 \mathrm{mg} /$ day, statistically significant difference was not seen in any of the lipid profiles. However, means of all follow up TC, LDL-C and TG were higher and all HDL-C were lower among those taking $75 \mathrm{mg}$ daily as compared to those taking $50 \mathrm{mg} /$ day.
TC at 24 months, LDL-C at both 6 and 24 months all were significantly different among patients taking various doses of prednisolone (Table 9).

Table 9: Lipid profiles with level of significance among different Prednisolone groups (according to doses and frequency).

\begin{tabular}{|ll|}
\hline Lipid profile & 'p’ value \\
\hline TC $(0)$ & $0.033^{*}$ \\
\hline TC $(6)$ & 0.068 \\
\hline TC $(12)$ & 0.071 \\
\hline TC $(24)$ & $0.007^{*}$ \\
\hline LDL-C $(0)$ & $0.022^{*}$ \\
\hline LDL-C $(6)$ & $0.014^{*}$ \\
\hline LDL-C $(24)$ & $0.003^{*}$ \\
\hline
\end{tabular}

\section{DISCUSSION}

The present data showed a dominance of 35-50 years age group among RTRs. This might be because the onset of HTN and DM, the two leading causes of renal failure lies within this age group. ${ }^{15}$ Further, mortality rate is higher in the elder renal failure patients too as compared to younger groups due to several risk factors including comorbidities. ${ }^{16}$ HTN seemed to be the most common cause of renal failure reason being a very large prevalence of HTN as compared to other causes of renal failure. ${ }^{17,18}$ This study showed a significant alteration of $\mathrm{f} / \mathrm{u}$ lipid levels as compared to baseline which has also been seen in various other studies as done by Kasiske BL and Umen AJ, Kasiske BL et al, and Miller LW., ${ }^{3,19}$ Findings are also consistent with studies done by $\mathrm{Tse} \mathrm{KC}$, et al in, Kimak E, et al in and Salahi $\mathrm{H}$, et al in. ${ }^{20-22}$

This study has shown an association of use of diuretics with increased lipid levels at 6 and 12 months. Association of diuretics with elevation in lipid levels has also been shown by the study done by Ames RP and Hill $\mathrm{P}$ in $1976 .{ }^{23}$

The finding of higher lipid levels with higher tacrolimus dose at 12 months as shown by this study supports the finding of the study done by Li HY et al in 2012 which has shown the relation of higher dose of tacrolimus blood concentration with hyperlipidemia at an early postoperative period. ${ }^{24}$ No significant impact of MMF in dyslipidemia in RTRs has been shown by this study, a finding consistent with some other studies too. ${ }^{3,25}$ Though the differences are not to a significant level, the pattern of lipid levels might suggest a positive correlation of dose of Azathioprine with lipid profile impairment. Further studies with more sample size and more variation in dose of azathioprine are required.

This study has demonstrated the association of use of prednisolone with alteration in lipid levels which and has been demonstrated and reasonably explained in various 
studies done in the past and is now a well-known fact. $^{3,8,11,12,26-28}$

No difference was seen to be statistically significant between the two immunosuppressive regimens i.e. none of the regimens was found to be superior over the other regarding lipid profile.

\section{CONCLUSION}

This study has concluded that lipid profile is significantly altered in patients after renal transplantation. Lipid levels seem to increase with age. Lipid levels seem to correlate with the dose of tacrolimus at 12 months. MMF seems to have no adverse impact on lipid profile and prednisolone is associated with alteration in lipid profile.

Hence, it is recommended that lipid profile should be regularly monitored in RTRs and appropriate measures applied, if necessary. Moreover physicians should consider preventive measures e.g. patients should be counselled regarding their diet and lifestyle considering the potential for lipid profile impairment and subsequent consequences.

Further, development of protocols/regimens that might have less adverse impact on lipid profile should also be considered in the future.

\section{ACKNOWLEDGEMENT}

Authors would like to thank, Professor Dr. Kumud Kumar Kafle, Dr. Sanu Maiya Shakya, Dr. Satish Kumar Deo, Dr. Pradip Gyawali, Dr. Anish Mudvari, Dr. Mahesh Raj Sigdel, Dr. Mukunda Prasad Kafle and Mr. Khadga Bahadur Shrestha.

Funding: No funding sources

Conflict of interest: None declared

Ethical approval: The study was approved by the Institutional Review Board of Institute of Medicine, Tribhuvan University, Nepal

\section{REFERENCES}

1. Treatment Methods for Kidney Failure: Transplantation. National Kidney and Urologic Diseases Information Clearinghouse (NKUDIC). NIH Publication. 2006 May. NIH Publication No. 064687.

2. Murray JE, Merrill JP, Harrison JH, Wilson RE, Dammin GJ. Prolonged Survival of Human-Kidney Homografts by Immunosuppressive Drug Therapy. N Engl J Med. 1963;268:1315-23.

3. Miller LW. Cardiovascular Toxicities of Immunosuppressive Agents. Am J Transplant. 2002;2(9):807-18.

4. Kasiske BL, Guijarro C, Massy ZA, Weiderkehr MR, Ma JZ. Cardiovascular disease after renal transplantation. J Am Soc Nephrol. 1996;7:158-65.
5. Kasiske BL, Chakkera HA, Roel J. Explained and unexplained ischemic heart disease risk after renal transplantation. J Am Soc Nephrol. 2000;11:1735-43.

6. Massy ZA. Hyperlipidemia and cardiovascular disease after organ transplantation. Transplantation. 2001;72:S13-5.

7. Kasiske BL. Epidemiology of cardiovascular disease after renal transplantation. Transplantation. 2001;72:S5-8.

8. Marcén R. Immunosuppressive drugs in kidney transplantation: impact on patient survival, and incidence of cardiovascular disease, malignancy and infection. Drugs. 2009;69(16):2227-43.

9. Weiner DE, Carpenter MA, Levey AS, Ivanova A, Cole EH, Hunsicker L, et al. Kidney Function and Risk of Cardiovascular Disease and Mortality in Kidney Transplant Recipients: The FAVORIT Trial. Am J Transplant. 2012;12:2437-45.

10. Israni AK, Snyder JJ, Skeans MA, Kasiske BL. Clinical diagnosis of metabolic syndrome: predicting new-onset diabetes, coronary heart disease, and allograft failure late after kidney transplant. Transpl Int. 2012;25:748-57.

11. Gunjotikar RV, Taskar SP, Almeida AF, Acharya VN. Dyslipoproteinemia in renal transplantation. J Postgrad Med. 1994;40:10.

12. Quaschning T, Mainka T, Nauck M, Rump LC, Wanner C, Krämer-Guth A. Immunosuppression enhances atherogenicity of lipid profile after transplantation. Kidney Int Suppl. 1999;71:S235-7.

13. Pannu HS, Singh D, Sandhu JS. Lipid profile before and after renal transplantation - a longitudinal study. Ren Fail. 2003;25(3):411-7.

14. Centers for Disease Control and Prevention. Interpretation of BMI for adults; 2014.

15. Durand ZW. Age of Onset of Obesity, Diabetes and Hypertension in Yap State, Federated States of Micronesia. Developing Human Resources in the Pacific. 2007;14(1):160-4.

16. Hartmann EL. Renal Transplantation in the Older Adult, in Geriatric Nephrology Curriculum. Geriatric Nephrology Curriculum, American Society of Nephrology; 2009:1-4.

17. Vaidya A, Pathak RP, Pandey MR. Prevalence of hypertension in Nepalese community triples in 25 years: a repeat cross-sectional study in rural Kathmandu. Indian Heart J. 2012;64(2):128-31.

18. Sharma SK, Ghimire A, Radhakrishnan J. Prevalence of Hypertension, Obesity, Diabetes, and Metabolic Syndrome in Nepal. Int J Hypertens. 2011:821971.

19. Kasiske BL, Umen AJ. Persistent hyperlipidemia in renal transplant patients. Medicine (Baltimore). 1987;66(4):309-16.

20. Tse KC, Lam MF, Yip PS, Li FK, Lai KN, Chan TM. A long-term study on hyperlipidemia in stable renal transplant recipients. Clin Transplant. 2004;18(3):274-80.

21. Kimak E, Solski J, Baranowicz-Gaszczyk I, Ksiazek A. A long-term study of dyslipidemia and 
dyslipoproteinemia in stable post-renal transplant patients. Ren Fail. 2006;28(6):483-6.

22. Salahi H, Jalaeian H, Nikeghbalian S, Davari HR, Bahador A, Roozbeh J, et al. The Comparison of Clinical and Biochemical Parameters among 1200 alive and dead Renal Transplant Recipients. Saudi J Kidney Dis Transpl. 2007;18:439-42.

23. Ames RP, Hill P. Elevation of serum lipid levels during diuretic therapy of hypertension. Am J Med. 1976;61(5):748-57.

24. Li HY, Li B, Wei YG, Yan LN, Wen TF, Zhao JC, et al. Higher Tacrolimus Blood Concentration Is Related to Hyperlipidemia in Living Donor Liver Transplantation Recipients. Dig Dis Sci. 2012;57(1):204-9.

25. Gallon L, Perico N, Dimitrov BD, Winoto J, Remuzzi G, Leventhal J, et al. Long-Term Renal Allograft Function on a Tacrolimus-Based, Pred-Free Maintenance Immunosuppression Comparing Sirolimus vs. MMF. Am J Transplant. 2006;6(7):1617-23.
26. Hricik DE, Mayes JT, Schulak JA. Independent effects of cyclosporine and prednisone on posttransplant hypercholesterolemia. Am J Kidney Dis. 1991;18(3):353-8.

27. Chan MK, Vargese Z, Persaud JW, Fernando ON, Moorhead JF. The role of multiple pharmacotherapies in the pathogenesis of hyperlipidemia after renal transplantation. Clin Nephrol. 1981;15(6):30913.

28. Bittar AE, Ratcliffe PJ, Richardson AJ. The prevalence of hyperlipidemia in renal transplant recipients: associations with immuno-suppressive and antihypertensive therapy. Transplantation. 1990;50(6):987-92.

Cite this article as: Lamichhane S, Bajracharya SR, Shah DS. Lipid profile in renal transplant recipients receiving immunosuppressive therapy. Int J Basic Clin Pharmacol 2017;6:393-8. 